\title{
A ANÁLISE DA INFORMAÇÃO E SEU ENSINO NOS CURSOS DE ARQUIVOLOGIA E BIBLIOTECONOMIA DA UNIVERSIDADE ESTADUAL DE LONDRINA: RELATO DE EXPERIÊNCIA
}

\author{
ROSANE ALVARES LUNARDELLI \\ LETICIA GORRI MOLINA** \\ IZÂNGELA SANSONI TONELLO ${ }^{* *}$ \\ ARETUSA MARQUES BARBOSA
}

\begin{abstract}
RESUMO
Os processos analíticos e sintéticos que possibilitam a representação da informação são essenciais à recuperação do universo informacional existente. De acordo com esse contexto, tem-se como objetivo, por meio de relato de experiência, evidenciar a disciplina Análise da Informação do Departamento de Ciência da Informação da Universidade Estadual de Londrina. Ofertada simultaneamente aos cursos de Arquivologia e Biblioteconomia, busca, em uma perspectiva multidisciplinar, subsidiar o tratamento temático da informação em diferentes tipologias documentais e em diversos contextos de uso. Caracterizada como matéria fundamental aos procedimentos de organização da informação por intermédio de sua descrição, torna-se
\end{abstract}

\footnotetext{
Possui graduação em Biblioteconomia, mestrado e doutorado em Estudos da Linguagem pela Universidade Estadual de Londrina. Pós doutorado em Ciência da Informação pela Universidade Federal da Paraíba. Professor Adjunto do Departamento de Ciência da Informação da Universidade Estadual de Londrina.

Graduação em Psicologia pela Universidade Estadual de Londrina (1993), graduação em Biblioteconomia pela Universidade Estadual de Londrina (2003) e mestrado pela UNESP/Marília, com título Portais Corporativos: tecnologias de informação e comunicação aplicadas à gestão da informação e do conhecimento em empresas de tecnologia de informação. Doutora do programa de pós-graduação em Ciência da Informação da UNESP/Marília, com tema: Memória Organizacional e a constituição de Bases de Conhecimento.

"Doutora em Ciência da Informação pela Universidade Estadual Paulista \& quot; Júlio de Mesquita Filho \& quot; (UNESP) em 2019. Mestre em Gestão da Informação pela Universidade Estadual de Londrina (UEL), em 2010. Especialista em Educação Infantil e Séries Iniciais pela Universidade Norte do Paraná (UNOPAR) em 2006. Graduada em Arquivologia em 2004 pela UEL.

**** Mestranda em Ciência da Informação como bolsista da CAPES Demanda Social. Participa como membro do Grupo de Pesquisa Metarrepresentações Informacionais em Ciência da Informação na Universidade Estadual de Londrina. Graduada no Curso de Biblioteconomia, da Universidade Estadual de Londrina.
} 
clara a necessidade de constante atualização na busca de melhores práticas de ensino e aprendizagem. Nesse sentido, espera-se contribuir para o estabelecimento de efetivos diálogos entre os docentes da Área que atuam nas diversas instituições de ensino superior.

PALAVRAS CHAVE: Análise da informação. Arquivologia. Biblioteconomia. Organização da informação.

INFORMATION ANALYSIS AND ITS TEACHING IN THE ARCHIVOLOGY COURSE OF LONDRINA STATE UNIVERSITY: REPORT ON THE EXPERIENCE

\begin{abstract}
The analytical and synthetic processes that enable the representation of information are essential to the recovery of the existing informational universe. Under this context, the purpose of this text is to, through experience report, make evident the subject matter Information Analysis of the Information Science Department at the State University of Londrina. Offered simultaneously to Archivologyand Librarianship courses, it intends to, in a multidisciplinary perspective, support the thematic treatment of information in different document types and in different contexts of use. Characterized as a fundamental subject matter to the organization procedures of information through its description, it becomes clear the need for constant updating in search of better teaching and learning practices. In this sense, it is expected to contribute to the establishment of effective dialogues between the teachers of the area involved in the various higher education institutions.
\end{abstract}

KEYWORDS: information analysis; archivology; librarianship; Information organization.

\title{
1. INTRODUÇÃO
}

A Ciência da Informação, por intermédio dos aportes teóricos e metodológicos da Arquivologia, Biblioteconomia e Museologia, tem como linha mestre de conduta, tornar a informação estruturada, acessível a quem dela necessite. Tal proposta concretiza-se pelos procedimentos de organização da informação, cuja principal ferramenta é a sua descrição ou representação.

No âmbito da Ciência da Informação, descrever e representar pressupõe análise, síntese, transposições de registros ou linguagens como, por exemplo, do código audiovisual para o textual ou numérico. Trata-se de processos intelectuais carregados de subjetividade e dificuldades, os quais demandam, por parte dos profissionais da informação, competências, habilidades específicas.

De acordo com essa premissa e com o intuito de propiciar condições para a capacitação de futuros profissionais da área, 
inseriu-se na estrutura curricular a disciplina Análise da Informação (AI) para os cursos de Arquivologia e Biblioteconomia do Departamento de Ciência da Informação da Universidade Estadual de Londrina (UEL), em seu tronco comum.

Considerando a importância de suscitar reflexões a respeito dos assuntos abordados e promover discussões entre os docentes da linha de Organização e Representação da Informação e do Conhecimento no contexto brasileiro, será apresentado, neste artigo, um relato de experiência acerca da oferta da disciplina e os conteúdos que a compõem, bem como a percepção dos alunos com relação à essa proposta. Como sustentação teórica para o relato de experiência, serão abordadas questões relativas à Análise da Informação e sua práxis no campo da Ciência da Informação, mais especificamente na Arquivologia e Biblioteconomia, e o esforço de inclusão dessa temática nos currículos dos dois cursos na UEL. Por fim, são apresentadas as percepções dos estudantes com relação à importância da disciplina e da oferta conjunta aos dois cursos de graduação, além das considerações finais do estudo.

\section{ANÁLISE DA INFORMAÇÃO}

De caráter eminentemente multidisciplinar, a Ciência da Informação, na perspectiva de Borko (1968, p. 3, tradução nossa), "[...] está preocupada com o corpo de conhecimentos relacionados à origem, coleção, organização, armazenamento, recuperação, interpretação, transmissão, transformação e utilização da informação." Dentre esse leque de ações apresentadas, cabe evidenciar a organização da informação, - "[...] processo que envolve a descrição física e de conteúdo dos objetos informacionais" (BRASCHER; CAFÉ, 2008, p. 5), como condição sine qua non ao acesso à informação e ao conhecimento nos mais variados contextos. Nas palavras de Lima e Alvares (2012, p. 34) "no domínio da organização estão os meios para recuperar a informação com vistas ao melhor desempenho e fidedignidade."

Organizar a informação pressupõe sua representação. Representar, nessa linha de raciocínio significa trazer de volta alguma coisa, descrevê-la, reapresentá-la.

De acordo com a semiótica pierciana, significa estar no lugar de. Entretanto, observa-se que representar ultrapassa o sentido de estar no lugar de uma vez que indica a retomada, a recuperação da informação citada no texto e que está presente no modelo contextual dos interlocutores. (LUNARDELLI; GALEMBECK, 2012, p. 177, grifo nosso). 
Representar o conteúdo informacional na Ciência da Informação tem como precípua finalidade a geração de produtos documentais como resumos, índices, catálogos, guias, inventários, palavras-chave, entre outros. Caracterizados como instrumentos de pesquisa/identificação/localização dos assuntos ou documentos tratados, são resultados de processos cognitivos de análise e síntese de alta subjetividade, os quais compõem a análise da informação. Em decorrência da complexidade em que se revestem essas ações, vale ressaltar a importância do processo mental que antecede a criação dessas representações documentárias ou informacionais, o qual se denomina de etapa analítica e tem como objetivo, como o próprio nome elucida, analisar a informação.

Segundo Baptista, Araújo Júnior e Carlan (2010, p. 63), em um contexto de valorização da informação e sua utilização para os mais diversos fins, pode-se observar que as pessoas se tornam, ainda que de modo geral, analistas da informação. Nessa perspectiva, de acordo com os autores, existem três níveis, intuitivo, racional e profissional -, em que se realiza a análise da informação. No nível intuitivo são acionados a intuição e o senso comum, e geralmente as situações são resolvidas sem a necessidade de maiores ponderações. O nível racional, em contrapartida, requer "níveis variáveis e crescentes de análise racional da informação, esteja esta contida nas circunstâncias da vida prática, na vida profissional [...]," independentemente do documento, do suporte, "sempre em função de um uso previsto e estabelecido pelo próprio usuário, e de resultados e repercussões potenciais ou imediatas em sua vida."

A análise da informação no nível profissional, foco desse estudo, é considerada pelos autores como sendo um processo "característico de algum tipo de mediação especializada que se torna necessária entre produtores e usuários da informação", com o propósito maior que é o de propiciar acesso a todo o tipo de informação registrada.

Outro enfoque a respeito desse modo intelectual de organização informacional, ainda acompanhando a linha de raciocínio de Batista, Araújo Júnior e Carlan (2010, p. 65-69), concretiza-se por intermédio de três dimensões. A primeira é sua dimensão conceitual, "[...] aquela que busca associá-la aos conteúdos temáticos da informação, identificando seu alcance e limites, estabelecendo interfaces disciplinares e objetivas que a caracterizam como uma das atribuições da ciência da informação." A segunda diz respeito à dimensão estratégica da informação, 
ou seja, "a decisão quanto ao projeto e implementação de formas diferentes de se organizar a informação com vistas à sua ágil recuperação [...]." A última dimensão, por sua vez, envolve "etapas e procedimentos de que justamente transformam o documento (recurso/-objeto) em informação disponível." Denominada de dimensão operacional, engloba todas as fases do processo de representação informacional.

Ainda que analisar, em seu sentido lato, seja inerente ao ser humano, a análise da informação ou documental no âmbito da Ciência da Informação segue padrões preestabelecidos ao invés de seguir apenas o "bom senso" ou intuição do profissional que a realiza. Nesse sentido, têm-se como procedimentos constituintes desse processo as etapas analíticas e a sintética em relação à informação.

$\mathrm{Na}$ etapa analítica são realizadas leituras técnicas (profissionais), com o intuito de identificar os assuntos mais relevantes para o usuário e aplicar "[...] ao documento um conjunto de categorias conceituais, visando à construção de enunciados de assunto." (GUIMARÃES, 2003, p. 112).

A etapa sintética diz respeito à seleção, condensação e representação dos conteúdos temáticos ou semânticos. Nessa fase, os enunciados de assuntos, como denomina Guimarães (2003), são classificados como "principais, secundários e ordenados logicamente, tendo como parâmetros a estrutura, a função e os usos (tipo de busca informacional a que se presta o documento)." Em posse desses conceitos procede-se à condensação (elaboração de resumos ou microtextos) e à representação documentária, "tradução do conteúdo temático de documento em linguagem de indexação [...]." (GUIMARÃES, 2003, p. 112-113).

Diante do exposto, pode-se afirmar que a análise da informação para a Arquivologia e Biblioteconomia é realizada com o objetivo de extrair conteúdos documentários de relevância para o usuário e representá-los de forma sintética, buscando obter o maior grau possível de similitude com o texto original.

As ações, os procedimentos acima mencionados, reitere-se, desvelam a complexidade desse processo uma vez que demandam, por parte dos profissionais, (efetivos mediadores), competências e habilidades como leitura e compreensão do conteúdo para fins documentários; identificação e seleção de assuntos e conceitos que mais se aproximem das necessidades informacionais dos usuários; conhecimento de tipologias e séries documentais; produção textual realizada de forma clara, concisa e com expressivo grau 
de similaridade com o documento fonte, bem como postura ética em todo o decorrer de suas atividades.

No que diz respeito ao contexto arquivístico, importa mencionar que a análise da informação se constitui base para a descrição arquivística, procedimento voltado aos arquivos permanentes, que possibilita a representação de um acervo específico por meio da identificação do conteúdo, do contexto de produção dos documentos e consequentemente da informação. Nas palavras de Lopez (2002, p. 12), "Somente a descrição arquivística garante a compreensão ampla do conteúdo do acervo, possibilitando tanto o conhecimento como a localização dos documentos que o integram."

De acordo com o Dicionário de Terminologia Arquivista (CAMARGO; BELLOTTO, 1996, p. 23) considera-se a descrição como um "conjunto de procedimentos que, a partir de elementos formais e de conteúdo, permitem a identificação de documentos e a elaboração de instrumentos de pesquisa."

Em outros termos cabe ressaltar que o propósito nuclear da descrição arquivística ou documentária é o de elaborar instrumentos de pesquisa, como o guia, o catálogo, o índice, o inventário, os quais são responsáveis pela "identificação, o rastreamento, a localização e a utilização de dados." (BELLOTTO, 2006, p. 179).

Para o campo da Biblioteconomia, a análise da informação propicia a sua representação, como a indexação, análise de assunto e seus produtos: designação de número de classificação, construção de resumos, palavras-chave e índices etc. Quando são transmitidas as teorias sobre a análise da informação para os estudantes de Arquivologia e Biblioteconomia, sua vertente maior é a análise de assunto, pois esse procedimento é mais utilizado dentro das unidades de informação. Segundo Cesarino e Pinto (1980, p. 32) "a análise de assunto é a operação-base para todo procedimento de recuperação de informações". Ou seja, todos os processos que existem dentro da Ciência da Informação precisam de uma base sólida de termos para o usuário poder recuperar a informação desejada. Por isso, essa disciplina é importante no momento da capacitação dos futuros profissionais da informação.

\section{CURRÍCULOS DOS CURSOS DE ARQUIVOLOGIA E BIBLIOTECONOMIA DA UEL E A DISCIPLINA ANÁLISE DA INFORMAÇÃO}

A importância de que se reveste a informação e o conhecimento em uma sociedade extremamente competitiva e em incessante transformação, demanda profissionais aptos a atuar, 
de forma eficiente e eficaz, na organização e disponibilização desse acervo informacional, dessa massa documental em expansão.

Nessa perspectiva, a educação surge como possibilidade de acesso e apropriação de um conjunto de informações sistematizadas, indispensáveis para a formação e capacitação igualitária do indivíduo como um ser ético, profissional e social. Conforme avalia Delors (1998, p. 12) compete à educação "[...] permitir que cada um venha a tomar consciência de si próprio e de seu meio ambiente, sem deixar de desempenhar sua função na atividade profissional nas estruturas sociais."

A sistematização e explicitação de elementos do saber, conteúdos a serem ensinados e aprendidos, materializam-se nas diversas concepções curriculares existentes. Nesse sentido, o currículo escolar, entendido como programa de formação, tem a função norteadora das atividades acadêmicas, uma vez que é "o conjunto daquilo que se ensina e daquilo que se aprende, de acordo com uma ordem de progressão determinada, no quadro de um dado ciclo de estudos". (FORQUIN, 1996, p. 188).

O currículo, nessa perspectiva, constitui-se em um processo de sistematização para formação escolar, ou seja, um projeto intrinsecamente imbuído de intencionalidade: o que se quer e o que se fará, - em qual espaço de tempo -, para alcançá-lo. Tem como objetivo contribuir com o indivíduo para o desenvolvimento de conhecimento e de capacidades, que resultará em profissionalismo, que é a forma como esse cidadão participativo e atuante contribuirá com a sociedade.

Dessa forma, importa salientar que um currículo deve ser pensado não como um transmissor de conhecimento, mas como um possibilitador para a aquisição desse conhecimento pelos alunos.

Na perspectiva de Sanfelice (2008, p. 2)

O currículo escolar é sempre produto de um contexto histórico determinado que, tendencialmente, será alterado quando as conjunturas socioeconômicas e político culturais se transformarem, dentro de um processo mais geral de permanências e mudanças da sociedade como um todo.

A escola, - seja ela voltada ao ensino fundamental, médio ou superior -, que realmente se comprometa com a qualidade do ensino, necessita ter um currículo dinâmico, flexível, que permita as abordagens interdisciplinares, transdisciplinares e multidisciplinares, que possibilite, ou melhor, que incentive a reflexão e a problematização de diversos conteúdos abordados. Outro aspecto 
a ser evidenciado diz respeito à importância de sua constante atualização e adequação ao momento social e histórico vivido.

Tendo em vista a característica extremamente articulada entre ensino e realidade do mundo do trabalho e a necessidade de alinhar esses dois aspectos, no ano de 2014, o Departamento de Ciência da Informação da UEL adotou um novo currículo no qual integra os cursos de Arquivologia e de Biblioteconomia. Tal situação não poderia ser diferente uma vez que a área da Ciência da Informação, - cujo objeto de estudos são as "[...] propriedades gerais da informação (natureza, gênese, efeitos), e a análise de seus processos de construção, comunicação e uso." (LE COADIC, 2004, p. 25), estabelece relações diretas com os cursos mencionados.

$\mathrm{Na}$ perspectiva do Conselho Nacional de Desenvolvimento Científico e Tecnológico (CNPq), a Ciência da Informação é considerada como uma grande área a qual abriga a Arquivologia, Biblioteconomia e Museologia, consideradas como subáreas. A Ciência da Informação, na perspectiva de Silva (2008, p. 8),

[...] nasceu no seio de uma sociedade multifacetada e complexa, é um campo constituído por múltiplas inserções que fazem interfaces com outros campos e áreas do conhecimento; esses, por sua vez, são também perpassados por multiplicidades de fenômenos.

Para a autora, essas são particularidades que evidenciam claramente a natureza multifacetada da Ciência da Informação, denotando tanto a sua interdisciplinaridade, como também a sua transversalidade.

Segundo Saracevic (1996), três características explicam a existência e evolução da Ciência da informação: sua interdisciplinaridade, sua estreita relação com a tecnologia da informação e sua dimensão social e humana. Para o autor, são estas características que permitem uma melhor compreensão do passado, presente e futuro da área e dos problemas e questões que ela enfrenta.

Durante muito tempo observou-se o distanciamento entre as subáreas ou, como tão bem denominou Smit (1993), entre as "três marias". Entretanto, segundo Cendón et al. (2008, p. 228), atualmente, "[...] o cenário científico acena para a busca da integração tendo como alicerce o novo modelo de interdisciplinaridade e do compartilhamento".

Nessa mesma linha de raciocínio, Smit (2003, p. [10]) defende a integração ao argumentar que "[...] as necessidades informacionais dos cidadãos-usuários dificilmente se enunciam em termos estritamente 'biblioteconômicos' ou 'arquivísticos."' A seguir, ressalta o 
fato de que "o mercado de trabalho vive enormes mutações, afastando-se a passos rápidos das distribuições anteriormente implantadas entre profissões regulamentadas." (SMIT, 2003, p. [10]).

Atualmente as configurações das sociedades modernas têm demandado mudanças urgentes e radicais na administração e nos métodos de trabalho. A complexidade desse novo desenho social, em parte ocasionada pela

[...] ruptura dos limites tradicionais de espaço e tempo para a circulação, sem barreiras, da informação constituída por dados alfanuméricos, voz, sons, imagem estática e imagem em movimento, como por exemplo, as multimídias. (SZLEJCHER, 2011, p. 29, tradução nossa).

Sustenta a devida articulação ou integração entre essas disciplinas do conhecimento.

Respaldado pelas questões apresentadas, o Departamento de Ciência da Informação da UEL, como anteriormente mencionado, propôs alterações significativas em suas concepções curriculares. Em decorrência, criou-se uma proposta de curso de Arquivologia em parceria com o de Biblioteconomia, concretizada pela existência de um tronco comum, cuja duração abrange dois anos, a ser cursado de forma conjunta, pelos ingressantes dos dois cursos. Nesse período, importa mencionar, as disciplinas ofertadas têm como intenção o estudo e a análise de questões no âmbito da Ciência da Informação, excetuando-se dois dias da semana no qual são ministradas disciplinas específicas de cada curso. Nos outros dois anos, cada curso tem sua estrutura curricular diferenciada, e cada um deles apresenta disciplinas e conteúdos específicos.

Cabe ressaltar que, para se alcançar os objetivo almejados nesse processo de integração dos currículos, o que ocasionou efetivamente uma mudança de paradigma, houve, a priori, por parte do corpo docente, a percepção da necessidade de alterações em relação às disciplinas ministradas, mudanças relacionadas ao desenvolvimento de metodologias e estratégias capazes de oportunizarem novas e crescentes habilidades intelectuais e práticas aos discentes. Outro fator determinante foram as demandas apresentadas em vários momentos, por alunos egressos das ofertas anteriores, como as que são apresentadas a seguir

- propiciar condições para que aconteça de fato a integração entre os cursos de Arquivologia e Biblioteconomia da Universidade Estadual de Londrina por meio da criação de um "tronco comum", 
disciplinas a serem oferecidas/cursadas em conjunto. Tal proposta é fato, fortalecerá ambos os cursos;

- investir na capacitação tecnológica de seus alunos com o aumento do rol de ofertas de disciplinas relacionadas a esse saber;

- aprimorar as habilidades de compreensão e produção de textos em língua portuguesa, inglesa e espanhola;

- capacitar os futuros egressos nos serviços de consultoria e assessoria em instituições públicas e privadas, espaços nos quais há grande demanda por arquivistas.

$\mathrm{O}$ atendimento a essas solicitações, entre outras, acredita-se, contribuem para aproximar os formandos do real mundo do trabalho que atualmente se descortina e que exige habilidades e competências múltiplas, desenvolvidas de forma ética e voltadas para o bem comum.

Dentre o rol de matérias que compõem o currículo dos cursos de Arquivologia e Biblioteconomia da UEL, é destacada nesse estudo, como anteriormente mencionado, a disciplina Análise da Informação.

\subsection{Análise da Informação: conteúdo programático da disciplina e percepção do professor}

Ofertada inicialmente no ano de 2014 ao primeiro ano dos cursos de Arquivologia e Biblioteconomia da UEL em seu tronco comum, a disciplina denominada Análise da Informação contava com 30 horas aulas de fundamentação teórica e 30 horas de práticas realizadas em sala de aula. Como procedimentos de ensino, constitui-se em aulas expositivas, dialogadas, com utilização de recursos audiovisuais; leitura e discussão de textos; estudos em grupos; e práticas de análise, condensação e representação de documentos/informações. Os instrumentos avaliativos abarcam provas dissertativas, apresentação de trabalhos/seminários e práticas relativas ao tema.

Como objetivos mais relevantes a disciplina busca suscitar reflexões acerca do papel da leitura na prática do profissional da informação; propiciar fundamentos teóricos e práticos à operação de leitura com vistas à organização da informação; e capacitar o estudante na representação de diversos conteúdos documentais por meio dos procedimentos da análise da informação.

Em seu conteúdo programático são promovidas explicações e discussões a respeito de temas como: Ciência da Informação; Organização da informação: enfoques temático e descritivo; Análise 
da Informação: nível intuitivo; temático; racional; Dimensão da Análise da Informação: conceitual; estratégica; operacional; a contribuição da Lógica, da Linguística, da Terminologia e da Diplomática na Análise da Informação; processos de Análise da Informação ou Análise Documental: etapa analítica e etapa sintética; leitura documentária; linguagens de representação da informação; produtos documentários da Análise da Informação/instrumentos de pesquisa: resumos, palavras-chaves, descritores, catálogos, inventários, sumário analítico, guias, índices; normas que subsidiam a elaboração desses produtos; e atividades práticas de análise e representação do conteúdo informacional de textos literários e científicos, fotografias, quadros, esculturas, moedas e documentos orais, como entrevistas, palestras etc.

Após quatro anos de sua implantação, os currículos dos cursos de Arquivologia e Biblioteconomia da UEL foram alterados, ou melhor, atualizados. A disciplina Análise da Informação (AI) passou a ter 15 horas teóricas e 15 horas práticas. Sua ementa também foi alterada para: processos e produtos de análise e síntese do conteúdo informacional. Continua sendo ofertada no primeiro ano para os dois cursos. As modificações ocorridas estão relacionadas à repetição em outras disciplinas, de alguns dos assuntos discutidos em sala de aula. Nesse sentido, a disciplina visa apresentar os pressupostos básicos da análise da informação em diversos tipos de documentos ou de textos, além de promover a prática da análise e síntese e sua representação em textos científicos, fotografias, quadros e esculturas.

Após ter ministrado a disciplina em suas várias ofertas, o professor responsável observa que a junção dos dois cursos apresenta-se benéfica uma vez propicia aos alunos o entendimento a respeito do papel da análise no contexto informacional seja ela sob à ótica dos procedimentos arquivisticos ou dos biblioteconômicos, promove a interação entre as duas área, entre outros aspectos.

No que tange à opinião dos alunos a esse respeito, como será apresentada a seguir, evidencia-se a semelhança com a do docente, ainda que sejam apontados aspectos negativos nessa proposta.

\section{PERCEPÇÃO DOS ESTUDANTES EM RELAÇÃO À DISCIPLINA COMO COMPLEMENTO AO RELATO DE EXPERIÊNCIA}

Caracterizando-se como a descrição da implantação de um currículo comum aos dois primeiros anos dos cursos de arquivologia e biblioteconomia, o estudo em pauta constitui-se em um relato de experiência. De modo a exemplificar esse processo apresentou-se a 
disciplina Análise da Informação, seus objetivos e conteúdos programáticos. Em complemento, com o intuito de referendar os aspectos ressaltados, buscou-se conhecer a percepção dos alunos a respeito da participação nos dois cursos em sala de aula. Nesse sentido, aplicou-se um questionário com três questões aos alunos dos segundos anos dos cursos de Arquivologia e Biblioteconomia da UEL que haviam cursado à referida disciplina.

A primeira pergunta era voltada à percepção dos discentes no que dizia respeito à disciplina. Para auxiliá-los na avaliação de percepção foi construído uma escala qualitativa de 10 níveis, com intervalo de 1 a 10, sendo o número 1 estipulado como muito ruim, o número 5 como médio e o número 10 como ótimo. A seguir é apresentado um gráfico com as respostas dos estudantes. Os números de 1 a 5 obtiveram $0 \%$ como resultado, por isso não foi incluído no gráfico. A maioria dos alunos assinalaram o número 8, 9 e 10 como uma medida positiva de satisfação em relação à disciplina.

Gráfico 1 - Respostas dos estudantes à questão "Qual a sua percepção a respeito da disciplina?"

\section{Respostas}

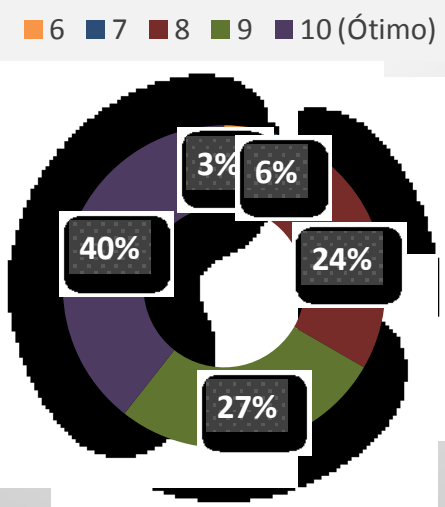

Fonte: elaborado pelas autoras.

Na segunda pergunta foram questionados os prós e contras da disciplina ser ministrada para os dois cursos concomitantemente. Esta questão era aberta para os estudantes responderem de forma discursiva ou em forma de tópicos. Houve muitas respostas positivas em relação à disciplina. As principais respostas foram: 
troca de conhecimento, experiências e interação entre os cursos; interação entre as áreas; importância para os dois cursos; auxilio na formação do aluno; agilizar na questão de ser poucos professores; favorece o currículo escolar; e, favorece a realização de tarefas praticas do fazer do bibliotecário ou arquivista.

Os pontos contras ou negativos foram: salas muito cheias; dificuldades para fazer os trabalhos; pouco tempo de aula; necessidade de mais aulas práticas; e, maior foco nos documentos tradicionais, como livros e documentos arquivísticos.

A última questão foi em relação a sugestões voltadas ao conteúdo da disciplina. As respostas foram as seguintes: a disciplina poderia ser anual, para melhor aproveitamento e aprofundamento das necessidades de cada curso; utilizar mais materiais não-convencionais (obras de arte, música, objetos 3D etc.); e visitas guiadas a unidades de informação, como museus, arquivos e bibliotecas.

Diante das respostas obtidas é possível observar a validade da proposta no que tange à união dos dois cursos ainda que aspectos como a necessidade de ampliação da carga horária, mais práticas com documentos não convencionais, visitas à diversos espaços informacionais tenham sido mencionados.

\section{CONSIDERAÇÕES FINAIS}

A estrutura curricular de um curso de graduação, as disciplinas ofertadas e as atividades prescritas tornam-se vital à formação dos profissionais das diversas áreas. Nesse contexto, cabe mencionar que a atualização constante, a flexibilidade, a inter, trans e multidisciplinaridade são critérios que tornam os currículos adequados à formação de boas práticas profissionais na atualidade. Outro aspecto digno de nota é a estreita relação que deve existir entre os conteúdos ofertados e o mundo do trabalho. Buscando atender aos aspectos mencionados, o Departamento de Ciência da Informação da UEL formulou uma proposta curricular que possibilita a integração dos cursos de Arquivologia e Biblioteconomia, com vistas a melhor formação e preparação dos profissionais para 0 mundo do trabalho.

Avalia-se que a inclusão da disciplina Análise da Informação, - cujo arcabouço teórico e metodológico pode ser considerado nucleares no âmbito dos saberes e fazeres no contexto da Ciência da Informação -, contribuiu sobremaneira para a qualidade da estrutura curricular apresentada. Nesse sentido, foram apresentados neste relato de experiência os conteúdos abordados na disciplina, bem como um breve estudo do estado da arte a respeito do assunto. 
Buscando ratificar a validade da proposta da união dos dois cursos em uma mesma sala de aula, investigou-se qual é a percepção dos discentes que participaram da disciplina Análise da Informação nos cursos de Arquivologia e Biblioteconomia da UEL. As respostas obtidas referendaram a premissa de que essa união se torna benéfica para a formação de novos profissionais da informação, favorecendo a formação mais ampla, a troca de experiências e a interdisciplinaridade.

A título de finalização e dada a importância de que se reveste um currículo em constante adequações, espera-se, com o relato de experiência da implantação em conjunto da disciplina de Análise da Informação, bem como a reestruturação ocorrida na atualização do currículo, além de suscitar reflexões a respeito, possibilitar a promoção de efetivos diálogos entre os docentes da área que atuam nas diversas instituições de ensino superior do Brasil.

\section{REFERÊNCIAS}

BAPTISTA, D. M.; ARAÚJO JR., R. H. de; CARLAN, E. Atributos dos requisitos funcionais para registros bibliográficos (FRBR). In: ROBREDO, Jaime; BRÄSCHER, Marisa (Orgs.). Passeios no Bosque da Informação: estudos sobre representação e organização da informação e do conhecimento. Brasília, DF: IBICT, 2010. Capítulo 3, p. 61-80. Disponível em: http://www.ibict.br/publicacoes/eroic.pdf. Acesso em: 03 jan. 2015

BELLOTTO, H. L. Arquivos permanentes: tratamento documental. 4. ed. Rio de Janeiro: Editora FGV, 2006.

BORKO, H. Information science: what is it?. American Documentation, Washington, v. 19, n. 1, p. 3-5, jan. 1968. Disponível em: https://onlinelibrary. wiley.com/doi/pdf/10.1002/asi.5090190103. Acesso em: 16 maio 2014.

BRASCHER; M.; CAFÉ, L. Organização da informação ou organização do conhecimento? In: ENCONTRO NACIONAL DE PESQUISA EM CIÊNCIA DA INFORMAÇÃO, 9., 2008, São Paulo. Anais [...]. São Paulo: ECA/USP, ENANCIB, 2008. Disponível em: https://www.ancib.org.br/media/ dissertacao/1835.pdf. Acesso em: 18 jul. 2013.

CAMARGO, Maria Albertina; BELLOTTO, Heloísa Liberalli. Dicionário de terminologia arquivística. 1996.

CESARINO, M. A. N.; PINTO, M. C. M. F. Análise de assunto. Revista de Biblioteconomia de Brasília, v. 8, n. 1, 1980. Disponível em: http://www.brapci.inf.br/index.php/res/v/72529. Acesso em: 03 maio 2019.

DELORS, J. (Org). Educação: um tesouro a descobrir. São Paulo: Cortez/Brasília: MEC: UNESC, 1998. Disponível em: https://unesdoc. unesco.org/ark:/48223/pf0000109590_por. Acesso em: 15 mar. 2015.

FORQUIN, Jean Claude. As abordagens sociológicas do currículo: orientações teóricas e perspectivas de pesquisa. Educação \& Realidade, 
v. $21, \quad$ n. 1, 1996. Disponível em: https://www.seer.ufrgs.br/ educacaoerealidade/article/view/71652.

GUIMARÃES, J. A. C. A Análise Documentária no Âmbito do Tratamento da Informação: Elementos Históricos e Conceituais. In: MEDLEG, G.; LOPES, I. L. (org.) Organização e representação do conhecimento na perspectiva da Ciência da Informação.Brasília: Thesaurus, 2003. (Estudos avançados em Ciência da Informação, 2)

LE COADIC, Yves-François. A Ciência da Informação. 2. ed. Brasília: Briquet de Lemos, 2004.

LIMA, J. L. O.; ALVARES, L. Organização e representação da informação e do conhecimento. In: ALVARES (Org.) Organização da Informação e do Conhecimento: conceitos, subsídios interdisciplinares e aplicações. São Paulo: B4 Editores, 2012, cap. 1, p. 21-48.

LOPEZ, A.P.A. Como descrever documentos de arquivo: elaboração de instrumentos de pesquisa. São Paulo: Arquivo do Estado, Imprensa Oficial, 2002. (Projeto Como Fazer, 6).

LUNARDELLI, R. S. A.; GALEMBECK, P. T. A metarrepresentação do assunto em resumos de textos científicos: reflexões iniciais de uma proposta de estudos. In: CERVANTES, B. M. N. (Org.). Horizontes da organização da informação e do conhecimento. Londrina: EDUEL, 2012. p. 173-191.

SANFELICE, J. L. A história da educação e o currículo escolar. - Quaestio: Revista de Estudos em Educação. São Paulo, ano IX, n. 24, p. 2-3, out. 2008. Disponivel em: http://periodicos.uniso.br/ojs/index.php?journal= quaestio\&page=article\&op=view $\&$ path $\% 5 \mathrm{~B} \% 5 \mathrm{D}=60$ \&path $\% 5 \mathrm{~B} \% 5 \mathrm{D}=60$.

Acesso em 10 maio 2016.

SARACEVIC, T. Ciência da informação: origem, evolução e relações. Perspectivas em Ciência da Informação, Belo Horizonte, v. 1, n. 1, p. 4162, jan./jun. 1996.

SILVA, T. Elisabeth da. (Org.). Interdisciplinaridade e transversalidade em Ciência da Informação. Recife: Néctar, 2008.

SMIT, J. W. Arquivologia/Biblioteconomia: interfaces das ciências da informação. Informação \& Informação, Londrina, v. 8, n. 2, jul./dez. 2003.

SMIT, J. W. O documento audiovisual ou a proximidade entre as três Marias. Revista Brasileira de Biblioteconomia e Documentação, São Paulo, v. 26, n. 1/2, p. 81-85, 1993.

SZLEJCHER, A. Investigación y formación Archivística: los nuevos desafios. In: MARQUES, A. A. da C.; RONCAGLIO, C.; RODRIGUES, G. M. (Org.). A formação e a pesquisa em Arquivologia nas universidades públicas brasileiras. Brasília: Thesaurus, 2011, p. 17-52. Disponível em: https://www.ufgd.edu.br/faed/nefope/publicacoes/curriculo-escolar-algumasreflexoes. Acesso em: 15 fev.2015.

Recebido em: 18/06/2019

Aceito em: 12/10/2019 